significant bacteriuria. In use the bactericidal activity of noxythiolin is dose- and timedependent; thus effective concentrations should be used in the management of stubborn infections. Inadequate exposure of organisms to noxythiolin should not be interpreted as resistance of the type threatening to compromise much conventional antibiotic use.

K G EDWARDS Medical Adviser

Chester Geistlich Pharmaceuticals

\section{Vertigo in children}

SIR - Your leading article on vertigo in children (5 November, p 1173) correctly states that "the fact that the child is experiencing vertigo may not be recognised" but omits to explain it. Children do not often complain of certain labyrinthine stimulations because they enjoy them, and you do not complain of what you enjoy.

On fairgrounds one can see large numbers of children queuing to pay for labyrinthine stimulations by swings, dippers, etc, which are totally unacceptable to adults because they would cause vertigo, and most adults would be prepared to pay for not having to endure them. It is this component of enjoyment (it ends with puberty) which complicates the issue, and which is most probably responsible for the standard textbook of paediatrics you quote not even mentioning vertigo in its index.

A B Alexander

London $\mathrm{W} 1$

\section{Hot flushes after hypophysectomy}

SIR, - With reference to the discussion by Mr G P Mulley and his colleagues of the cause of hot flushes during the menopause (22 October, $\mathrm{p}$ 1062), the following case may serve as an illustration.

A 31-year-old woman had started having headaches at the age of 12 . She improved slightly after glasses had been prescribed but at a routine eye examination three years later bitemporal hemianopia was found and a pituitary tumour diagnosed. She underwent an uncomplicated transfrontal removal of a chromophobe adenoma and irradiation with $3900 \mathrm{R}$ was given. For the next nine years she was fairly well but did not menstruate.

At age 24, when we saw her for the first time, she was childish and pale, without either mammary gland tissue or axillary hair, and had only scanty pubic hair. The visual field defects (bitemporal hemianopia) had remained unchanged since the operation. She had partial hypopituitarism. Urinary steroids were low, without metyrapone response but normal ACTH response. The serum growth hormone concentration was low and did not rise after arginine infusion. The serum luteinising hormone ( $\mathrm{LH})$ concentration was slightly elevated at $7.9 \mu \mathrm{g} / 1$. Thyroid function was normal. Replacement therapy with cortisone $12.5 \mathrm{mg}$ and diethylstilboestrol $0.5 \mathrm{mg}$ daily was initiated. Eight months later, after satisfactory feminisation, the stilboestrol therapy was changed to cyclic administration with the addition of norethisterone on the last five days of the 21-day period of treatment. With cyclic therapy she has since had regular vaginal bleeding.

After seven years the diethylstilboestrol treatment was temporarily stopped so that prolactin secretion could be examined. Almost exactly 14 days later she suddenly experienced hot flushes 5-6 times daily lasting for a few minutes. The flushes were also noted by her friends, who teased her about "the change of life." She could not remember having experienced hot flushes either before operation or during the nine years that had elapsed between operation and the start of substitution therapy. The serum concentrations of $\mathrm{LH}$, folliclestimulating hormone (FSH), and prolactin were measured during and two weeks after the withdrawal of substitution therapy. The $\mathrm{LH}$ and FSH values were within normal limits on both occasions; that of prolactin was elevated $(36 \mu \mathrm{g} / \mathrm{l})$ when the patient was on oestrogen but fell to normal $(11.5 \mu \mathrm{g} / \mathrm{l})$ later.

Our patient supports the theory that lack of oestrogen and not gonadotrophin excess is the cause of hot flushes during the menopause. It has to be noted, however, that the hot flushes occurred in a previously "well-oestrogenised" woman and were absent before oestrogen therapy was instituted (even if the LH level then was slightly elevated).

\section{INGEGERD FRgYSHOV LARSEN}

Section of Endocrinology

Medical Department B, and

Medical Department A

University Hospital

Rikshospitalet,

\section{(1)}

Doctors and the global population crisis

SIR,-Dr Peggy Norvis and the World Federation of Doctors Who Respect Human Life (29 October, p 1154) seem to be confusing two different concepts. To "respect human life" and to "maintain the utmost respect for life from the moment of conception" are not different expressions of the same belief, nor will they lead to the same course of action. Those doctors who welcomed the 1967 Abortion Act cannot be dismissed conveniently as denigrators of human life or deviators from the conventional code of medical ethics. It is precisely their respect and concern for the life of the woman and the potential life of the fetus which are major determinants in their decision to perform an abortion.

Similarly, it is this respect and concern for human life which is the motive behind those doctors who are pressing for further liberalisation of abortion in this country. Even in those parts of the United Kingdom where abortions are relatively easy to obtain the decision to allow the abortion remains in the hands of the medical profession. Our respect for human life leads us to believe that the decision about abortion should be made by the woman herself, and we strongly advocate legislation for a woman's choice on abortion.

Sheila Adam

Oxford

\section{$\varnothing v[$ rith \\ Treatment of hepatic hydatid disease}

SIR,-We read with interest the article by Dr A Bekhti and others (22 October, p 1047) on the treatment of hepatic hydatid disease with mebendazole. We have undertaken several therapeutic trials of hydatidosis with different drugs and have treated one patient with flubendazole, a fluoro derivative of mebendazole.

The patient, a 31-year-old Algerian, was operated on in November 1976 for multiple hepatic and peritoneal cysts. At operation total removal of the existing cysts was not possible. Before operation the titre of antibodies by passive haemagglutination was 6400 (positive, $>1600$ ) and the arc 5 specific for hydatidosis was demonstrated by immunoelectrodiffusion. Specific hydatid IgE antibodies were measured by a radioimmunoassay using tubebound antigen ${ }^{1}$ and were found to be normal. Tests for immune complexes by precipitation of radiolabelled $\mathrm{Clq}$ by polyethylene glycol $^{2}$ and the Raji cell assay ${ }^{3}$ showed them to be absent.

No changes were seen in the levels of specific $\mathrm{IgE}$ antibodies or immune complexes in the serum samples obtained monthly from the patient; there was, however, a significant decrease in the titre of antibodies by haemagglutination six months after the surgical intervention (800).

In July 1977 the patient was treated with $1 \mathrm{~g}$ of flubendazole daily by mouth for 14 days and this treatment was repeated in August. The last serum sample obtained in October showed a rise in the titre of antibodies by haemagglutination to 12800 ; the level of specific IgE remained unchanged and immune complexes were always absent. Clinically there appeared to be an improvement in the patient's general health after treatment. However, the rise in the level of antibodies by haemagglutination suggested that the hydatid cysts were not in a state of regression.

The difference in efficacy of treatment compared with the cases reported by $\mathrm{Dr}$ Bekhti and his colleagues could be due to the different localisation of the cysts in our patient, since the cases reported by those authors had only hepatic cysts. Another possibility is that owing to the reported poor absorption of the drug the dose given was insufficient.

The suggestion by Dr Bekhti and his colleagues that specific IgE antibodies and immune complexes are useful for assessing the efficacy of treatment remains to be confirmed since in our study of 30 cases of clinically confirmed hydatidosis only $30 \%$ had raised specific IgE antibodies and immune complexes in their serum. It would thus seem that these criteria can only be used in a small proportion of patients with hydatid disease.

\section{DANIS D RICHARD-LENOBLE G BRÜCKER MARY SMITH M Gentilini}

Paris,
France

' Richard-Lenoble, D. In preparation

ydeggar, U, et al, Schweizerische medizinische (1074, 104, 126 gation, 1976, 57, 169 .
gournal of Clinical Investi-

\section{Relapse in leprosy}

SIR,-As a leprosy field worker in India I found your leading article on relapse in leprosy (8 October, p 914) very interesting. The problem of dapsone resistance is real, as highlighted by the recent symposium on dapsone resistance in the Leprosy Review (June 1977). Some very important issues have been raised. However, one wonders if your article is aimed at developed countries with little leprosy and large resources or at those areas of the world where leprosy is still a major problem and where limited resources are the hard facts of life. Does what is "permissible" differ in the two areas? I wonder if, in many control programmes in the developing countries of the world, you leave us with a choice between what is no longer "permissible" and what is not possible.

Considering the high costs, multiple drug therapy of patients in many cases may not be feasible. We should note that we do not yet have sufficient results of long-term combination drug trials convincing us of their costeffectiveness and whether they will effectively 